\title{
Editorial
}

\section{La inteligencia artificial como herramienta para avanzar en urología}

\author{
Herney Andrés García-Perdomo ${ }^{10}$ \\ ${ }^{1}$ Departamento de Cirugía/Urología, Escuela de Medicina, \\ Universidad del Valle, Cali, Colombia
}

Urol Colomb 2020;29:1-2.

Como médicos, cirujanos, investigadores y académicos, nos enfrentamos a diferentes retos en los entornos en los que actuamos. Todos conocemos el complicado proceso de la toma de decisiones y la importancia de evitar errores de juicio en cada paso: Cuando se define un diagnóstico, se abordan los factores de riesgo modificables, se optimiza el uso de los recursos, se ofrece o se realiza una cirugía y se manejan las complicaciones. ${ }^{1}$

En la actualidad, el elevado volumen de datos, su disponibilidad y las diferentes fuentes existentes podrían impedir la síntesis de información adecuada para obtener un diagnóstico preciso, planificar un tratamiento individualizado y obtener la predicción de un resultado. ${ }^{2}$ Comúnmente confiamos en los métodos estadísticos, que son las herramientas que leemos en los estudios publicados, no obstante, los clínicos e investigadores han aplicado métodos de la inteligencia artificial (IA) en diferentes áreas de conocimiento. Específicamente en las enfermedades urológicas, durante años superando los métodos estándar ${ }^{3,4}$ para superar el problema al que nos enfrentamos cada día en nuestro proceso de toma de decisiones.

La IA es una herramienta crítica que se centra en la creación de un algoritmo inteligente que realiza tareas humanas por medio de complejos modelos matemáticos no lineales y bloques de construcción que imitan a las neuronas humanas. El objetivo principal es aprender fácilmente y desafiar las capacidades humanas para mejorar un resultado determinado., ${ }^{1,2}$ Por lo tanto, los diferentes tipos de IA reflejan sistemas informáticos que pueden aprender de los datos brutos con un cierto grado de autonomía, por ejemplo, el aprendizaje automático, las redes artificiales, el proceso de aprendizaje natural, el aprendizaje profundo y el de refuerzo, entre otras. ${ }^{5}$

El aprendizaje automático (AA) es un subtipo de IA en el que hay ciencia y aplicación de modelos estadísticos y algoritmos que pueden inferir patrones a partir de datos primarios. Este método fue uno de los primeros de este tipo y demostró que no había necesidad de escribir códigos largos, sino que se le podría enseñar a las máquinas a detectar un patrón. Algunos ejemplos incluyen el reconocimiento de voz, los motores de búsqueda en la web y los filtros de correo electrónico. ${ }^{2}$ Existen dos modelos, supervisados y no supervisados. El primero se refiere a los sistemas que pueden inferir un resultado prescrito o una categoría de salida a partir de datos primarios mediante algunas instrucciones de expertos humanos, en otras palabras, el sistema debe ser capacitado para aprender una asociación entre los datos de entrada y la salida (resultado). El modelo no supervisado crea sus categorías de salida a partir de la estructura y distribución de los datos de entrada sin entrenamiento específico. ${ }^{1}$

Otro tipo interesante de IA son las redes neuronales artificiales (RNA) y el aprendizaje profundo (AP). Se asemejan a un sistema nervioso biológico en el que las señales se encuentran en capas de unidades computacionales simples (neuronas); las conexiones entre las unidades están ponderadas pero pueden cambiar a medida que la red aprende diferentes patrones de entrada/salida. ${ }^{6}$ La red de aprendizaje profundo es una red neuronal artificial altamente dimensional, con múltiples capas que apoyan el descubrimiento de representaciones ocultas y abstractas en los datos en bruto. Esos nodos y capas ocultos son ponderados e influenciados por las capas anteriores a medida que aprende $\mathrm{e}^{1,2}$

Por otro lado, el aprendizaje de refuerzo es otro tipo de IA en el que los sistemas informáticos pueden identificar las acciones que dan la mayor probabilidad de un resultado determinado. En este subtipo, el modelo puede entrenarse mediante escenarios de prueba y error (algoritmos) para encontrar estas acciones. ${ }^{1}$

El procesamiento del lenguaje natural comprende un sistema que puede entender el lenguaje humano escrito y hablado. Este tipo de IA es crucial para el análisis de registros médicos electrónicos a gran escala, especialmente para los
Address for correspondence Herney Andrés García-Perdomo, MD MSc EdD PhD, FACS, Departamento de Cirugía/Urología, Escuela de Medicina, Universidad del Valle, Cali, Colombia (e-mail: editorrevista@scu.org.co).
DOI https://doi.org/ 10.1055/s-0040-1709123. ISSN 0120-789X. e ISSN 2027-0119.
Copyright ( $)$ 2020, Sociedad Colombiana License terms de Urología. Publicado por Thieme Revinter Publicações Ltda., Rio de Janeiro, Brazil. Todos los derechos reservados.

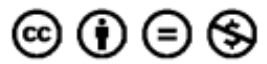


datos narrativos de los médicos (historias clínicas). Este identificará la información estándar para encontrar relaciones. ${ }^{2}$

Hasta ahora he descrito diferentes subtipos de IA, pero a partir de aquí, describiré algunos ejemplos de las aplicaciones clínicas en urología.

La mayoría de las aplicaciones son descritas en el cáncer genitourinario en lo que respecta al diagnóstico, la estadificación y el pronóstico. Además, de acuerdo con los nuevos avances en las ciencias ómicas, los investigadores también han puesto su atención en nuevos biomarcadores y en la extracción de datos mediante técnicas bioinformáticas (tecnologías computacionales y estadísticas para el análisis de datos biológicos) que también utilizan herramientas de IA.

En el cáncer de próstata, existen AA y RNA que han mostrado una mejora en la precisión del diagnóstico en algunos escenarios, especialmente en aquellos con patología digital y Resonancia magnética (RM) de la próstata. Sin embargo, en otros, como la estadificación y el pronóstico, algunos modelos de IA demostraron ser superiores a las herramientas estadísticas estándar, mientras que otros encontraron resultados similares. ${ }^{2,6}$

En cuanto al cáncer urotelial, el uso de imágenes y marcadores de metabolitos de la orina basados en modelos de IA podría mejorar el diagnóstico del cáncer de vejiga y urotelial (AUC 0,7 a 0,9). También será esencial para disminuir la variabilidad entre los observadores. Además, puede mejorar el pronóstico en pacientes con la enfermedad invasiva del músculo. ${ }^{2,7}$

El cáncer renal puede ser un reto, especialmente durante el proceso de diagnóstico. Los datos clínicos y metabolómicos basados en la espectroscopia y la espectrometría de masas podrían utilizarse en los instrumentos de IA y mejorar la precisión del diagnóstico con respecto a los métodos estadísticos o de diagnóstico por imágenes convencionales. ${ }^{2,8}$

Otros escenarios de la urología son la hidronefrosis y el reflujo urinario. Hay estudios que intentan predecir el reflujo urinario y la obstrucción renal a partir de la ecografía basada en AA. Los autores encontraron que son ligeramente mejores que las herramientas estadísticas estándar.9,10

La IA es una herramienta excitante y esencial para apoyar la toma de decisiones clínicas para los urólogos. No hay suficientes datos en este momento para estandarizarla; sin embargo, esta es una herramienta que ha demostrado ser útil. Necesitamos trabajar junto con el científico de datos, el bioestadístico, el biólogo molecular y otros profesionales que puedan colaborar para entrenar estos métodos para mejorar la salud de nuestros pacientes.

Conflicto de Interesses

Los Autores Declaran No Tener Ningún Conflicto De Intereses.

\section{Referencias}

1 Loftus T, Tighe P, Filiberto A, Efron P, Brakenridge S, Mohr A. y otros. Inteligencia artificial y toma de decisiones quirúrgicas. JAMA Surg 2019

2 Chen J, Remulla D, Nguyen JH, Aastha D, Liu Y. Dasgupta, y otros. Situación actual de las aplicaciones de la inteligencia artificial en la urología y su potencial para influir en la práctica clínica. BJU Int 2019;124(04):567-577

3 Drouin S, Yates D, Hupertan V, Cussenot O, Roupret M. Una revisión sistemática de las herramientas disponibles para predecir la supervivencia y el manejo de los pacientes con carcinomas uroteliales de la vejiga y del tracto superior en un entorno curativo. Mundo J Urol 2013;31:109-116

$4 \mathrm{Kim}$ J, Yook I, Choi M. Una comparación de rendimiento en los clasificadores de aprendizaje por máquina en la estadificación de la patología predictiva del cáncer de próstata. Stud Heal Technol Inf 2017;245:1273

5 Hashimoto DA, Rosman G, Rus D, Meireles OR. Inteligencia artificial en cirugía: promesas y peligros. Ann Surg 2018;268 (01):70-76

6 Abbod MF, Catto JWF, Linkens DA, Hamdy FC. Aplicación de la inteligencia artificial al manejo del cáncer urológico. J Urol 2007; 178(04):1150-1156

7 Xu X, Zhang X, Tian Q. Características de textura tridimensional de los mapas de intensidad y derivados de alto orden para la discriminación entre los tumores de vejiga y los tejidos de la pared por medio de la resonancia magnética. Int J Computer Assist Radiol Surg 2017;12:645-656

8 Haifler M, Pence I, Sun Y. Discriminación de tejido renal maligno y normal con espectroscopia Raman dispersiva de onda corta. J Biofotónica 2018;11:e201700188

9 Logvinenko T, Chow J, Nelson C. Valor predictivo de los hallazgos específicos de los ultrasonidos cuando se usan como prueba de detección de anormalidades en el VCUG. J Pediatr Urol 2015; 11:176.e1-7

10 Cerrolaza JJ, Peters CA, Martin AD, Myers E, Safdar N, Linguraru MG. Ecografía cuantitativa para medir la gravedad de la obstrucción en niños con hidrofenosis. J Urol 2016;195(4 Pt 1):1093-1099 